\title{
PSICOLOGIA CULTURAL, AUTOBIOGRAFIA E PESOUISAS EDUCACIONAIS: APLICAÇÕES EM CONTEXTO AMAZÔNICO
}

\author{
Elizabeth A. L. M. Martines1
}

\section{Maria Isabel da Silva Leme2}

\section{Suzana Rocha Souza de Azevedo ${ }^{3}$}

\section{Marcelo Luiz da Silva ${ }^{4}$}

\begin{abstract}
Resumo: Este trabalho tem por objetivo discutir os fundamentos da autobiografia na Psicologia Cultural proposta por Jerome Bruner e divulgar pesquisas que estão sendo realizadas em contextos escolares amazônicos apoiadas neste referencial teórico. Consideramos o tema proposto relevante por ser a Psicologia Cultural pouco utilizada no Brasil e a adoção na pesquisa nesta perspectiva permitir não só uma compreensão mais completa do funcionamento psicológico, mas ainda, a compreensão de processos sociais que diferem em sua natureza do funcionamento individual. Os autores representam três gerações de pesquisadores que vêm utilizando fundamentos e métodos desta abordagem teórico-metodológica em contextos escolares da Amazônia Legal.
\end{abstract}

Palavras-chave: Psicologia Cultural. Autobiografia. Pesquisa Aplicada.

\section{INTRODUÇÃO}

Este trabalho apresenta os fundamentos de uma produção acadêmica iniciada a partir da orientação da Dra. Maria Isabel da Silva Leme (IP/USP) em tese de doutorado da primeira autora sobre currículo de Ciências Biológicas na Universidade Federal de Rondônia. Em seu grupo de pesquisa Laboratório de Ensino de Ciências (EDUCIENCIA), a referida pesquisadora vem orientando dissertações

\footnotetext{
1 Laboratório de Ensino de Ciências (EDUCIENCIA) / Universidade Federal de Rondônia (UNIR), Porto Velho / RO. bethmartines@gmail.com.

2 Instituto de Psicologia / Universidade São Paulo (USP), São Paulo / SP. belleme@usp.br.

3 Instituto Federal de Educação, Ciência, Tecnologia de Rondônia (IFRO), Porto Velho / RO. suzanamusica@gmail.com.

4 Instituto Federal de Educação, Ciência, Tecnologia de Mato Grosso (IFMT), Alta Floresta /MT. marcelo. silva@alf.ifmt.edu.br.
} 
e teses dentro da perspectiva proposta por Bruner.

A Psicologia Cultural foi proposta por Jerome Bruner nos EUA no final do século passado buscando superar a distorção que este autor via na Psicologia Cognitiva, que ajudara a fundar na década de 1950. No seu entender, a Psicologia Cognitiva havia se transformado em uma abordagem do psiquismo humano tecnicista e diversa do que os seus fundadores haviam almejado para substituir o Behaviorismo. Assim, com a proposta da Psicologia Cultural pretendia resgatar o papel do significado na experiência humana (Leme, 2001). Com isso ele lança os fundamentos teóricos para uma nova visão de investigação da mente e da cultura na psicologia contemporânea, estabelecendo ainda relações importantes com a educação.

Nesta abordagem a relação individuo-cultura é concebida como não determinística, no sentido da influência da cultura sobre o indivíduo, mas principalmente porque tampouco ela é concebida como um mosaico das subjetividades que nela convivem, como uma somatória das contribuições individuais. O funcionamento cultural transcende o individual, tendo um tipo de conhecimento partilhado e implícito sobre como se relacionar, como organizar e interpretar a experiência, como relatá-la e transmiti-la. É justamente este aspecto que é considerado uma das formas produtivas de estudar a cultura, isto é, por meio de narrativas, notadamente as autobiográficas, as quais permitem observar não só como o indivíduo representa sua identidade cultural, concebida aqui como a representação de si mesmo como protagonista de uma história que confere significado à sua existência, mas ainda como a organiza para seu ouvinte.

As narrativas autobiográficas permitem observar o funcionamento psicológico na cultura, a constituição cultural da identidade, diferenças culturais e outras informações importantes, propondo uma ferramenta importante para a identificação e compreensão dessas diversas informações. Este trabalho tem por objetivo discutir os fundamentos da autobiografia na abordagem psicocultural proposta por Jerome Bruner e sua aplicação no campo educacional, trazendo alguns exemplos de como estes fundamentos veem sendo aplicados em pesquisas na região amazônica. 


\section{A ABORDAGEM PSICOCULTURAL PROPOSTA POR J. BRUNER E CURRÍCULO}

O primeiro trabalho aqui focalizado, realizado sob a orientação da Dra. Maria Isabel da Silva Leme, foi a tese de doutorado de Martines (2005) que estabelece relações entre psicologia e currículo, mais especificamente, entre a Psicologia Cultural, a autobiografia e a pesquisa sobre currículos. A autora demonstra que a valorização da autobiografia no campo do currículo surge com o movimento de reconceitualização do currículo ocorrido nos Estados Unidos na década de 1970. Este acabou dissolvido no pós-estruturalismo, no feminismo, nos estudos culturais e, atualmente, este termo ficou limitado às concepções fenomenológicas, hermenêuticas e autobiográficas de crítica aos modelos tradicionais de escolarização e de currículo.

Para esta perspectiva o currículo não é, pois, constituído de fatos, nem mesmo de conceitos teóricos e abstratos: o currículo é um local no qual docentes e aprendizes têm a oportunidade de examinar, de forma renovada, aqueles significados da vida quotidiana que se acostumaram a ver como dados e naturais. $\mathrm{O}$ currículo é visto como experiência e como local de interrogação e questionamento da experiência: questiona-se primeiro as próprias categorias do currículo acadêmico tradicional, tais como disciplinas, objetivos, avaliação etc., consideradas todas elas como "[...] conceitos de segunda ordem, que aprisionam a experiência pedagógica e educacional do mundo vivido de docentes e de estudantes" (SILVA, 2000, p. 40).

A atitude fenomenológica envolve, primeiramente, uma seleção de temas que fazem parte da vida rotineira. A análise fenomenológica implica numa demorada introspecção e reflexão sobre os significados das experiências vividas relacionadas com aquele tema, bem como os significados que outras pessoas atribuem à situação e como estas situações foram descritas significativamente na literatura ou na arte. Esta análise termina numa escrita fenomenológica, na qual seu/sua autor/a reconstitui a experiência vivida através da linguagem (sempre uma experiência de segunda ordem).

Segundo Silva, na teorização sobre currículo, a análise fenomenológica tem sido frequentemente, combinada com duas outras estratégias de investigação: a hermenêutica e a autobiografia. A hermenêutica contemporânea "[...] destaca, em contraste com a suposta existência de um significado único e determinado, a possibilidade de múltipla interpretação que têm os textos - [...]" entendidos aqui, não apenas como o texto escrito, mas como qualquer conjunto de significados 
(SILVA, 2000, p. 41).

Quanto à autobiografia como forma narrativa, consiste num método ou técnica que começou a ser valorizada no meio científico só muito recentemente, embora para Bruner, ele constitua um modo de pensamento, complementar ao pensamento argumentativo (lógico-matemático ou paradigmático), altamente significativo na constituição de nossas singularidades e organização da experiência, estando presente em todas as culturas humanas (BRUNER, 1997b, p.12).

William Pinar, por exemplo, recorre ao significado original de curriculum que significa pista de corrida e se relaciona com o verbo correr -, para enfatizar que o currículo deve ser compreendido como uma atividade, um "percorrer a pis$t a$ ", mais do um substantivo, uma coisa, e que não se limita à nossa vida escolar, educacional, mas pode ser compreendido como ato ligado à nossa vida inteira. $\mathrm{O}$ método autobiográfico, na visão de Pinar, permite relacionar o individual com o social de uma forma que os outros métodos não fazem, não se limitando a “[...] desvelar os momentos e aspectos formativos da nossa vida educacional e pedagógica: ele próprio tem uma dimensão formativa, autotransformativa" (SILVA, 2000, p. 43).

\subsection{O PRECEITO DA RESTRIÇÃO E O PODER DA METACOGNIÇÃOO NO DESEŇVOLVIMENTO DO SER HUMANO}

Uma perspectiva cultural-psicológica sobre educação (BRUNER, 2001) admite alguns preceitos que fundamentam essa abordagem, entre eles, o preceito da restrição, segundo o qual, a produção de significados acessíveis ao ser humano em qualquer cultura é restringida de duas maneiras: como seres resultantes de uma espécie em evolução somos especializados em determinadas maneiras de sentir, pensar, saber e perceber, isto é, temos predisposições inatas ou naturais de pensar e interpretar o mundo de uma determinada forma, que colocam restrições sobre nossa forma de interpretar e compreender. ${ }^{5}$

Entretanto, embora admitamos uma herança genética na determinação do dote humano, esse não deve ser considerado "fixo", pois, embora sejam "[...] comuns à espécie, refletem como representamos o mundo por meio da linguagem e das teorias populares - e elas não são imutáveis" (BRUNER, 2001, p. 27). Assim, apesar de nosso dote inato, tudo indica que também temos uma Zona de Desenvolvimento Imediato (VIGOTSKI, 2000) que nos permite reconhecer caminhos além deste dote. 
A segunda restrição, segundo Bruner, abrange as restrições impostas pelos sistemas de símbolos acessíveis às mentes humanas, tanto os limites impostos pela própria natureza da língua, como as "[...] restrições impostas pelas diferentes línguas e sistemas notacionais acessíveis a diferentes culturas” (BRUNER, 2001, p. 27). As inúmeras pesquisas na área da linguagem não são conclusivas sobre os seus limites, mas, sabe-se que o dote metalinguístico ou a metacognição é uma ferramenta poderosa do ser humano.

\begin{abstract}
Tudo que se sabe com certeza é que a consciência ou a 'conscientização linguística' parece reduzir as restrições impostas por qualquer sistema simbólico. As vítimas reais dos limites da linguagem são aqueles que estão menos conscientes da língua que falam. [...] Já que os limites de nossas predisposições mentais inerentes podem ser transcendidos recorrendo-se a sistemas simbólicos mais poderosos, uma função da educação seria equipar os seres humanos com sistemas simbólicos necessários para fazê-lo. E se os limites impostos pelas línguas que utilizamos são expandidos aumentando-se nossa 'consciência linguística', então uma outra função da pedagogia seria cultivar tal conscientização. Talvez não sejamos capazes de transcender todos os limites impostos em cada um dos casos, mas certamente podemos aceitar o objetivo mais modesto de melhorar, dessa forma, a capacidade humana de interpretar significados e construir realidades. Em suma, portanto, 'pensar sobre pensar' deve ser um ingrediente principal em qualquer prática da educação que delegue poderes (BRUNER, 2001, p. 28).
\end{abstract}

Assim, esta corrente psicológica aplicada à educação enfatiza os poderes " $d a$ consciência" (conscientização ou metacognição), "da reflexão", "da amplitude do diálogo" e da "negociação" para a superação das restrições impostas por nosso dote inato (BRUNER, 2001, p. 46). Estes preceitos emergiram, principalmente, de estudos sobre "[...] os meios pelos quais professores e alunos realizam suas atividades em salas de aula na vida real - como os professores ensinam e como os alunos aprendem" (p. 89).

Um preceito da abordagem cultural-psicológica aplicada à educação destacada por Bruner é a reflexão, fundamental no processo de tomada de consciência: “[...] fazer sentido, ir para o nível 'meta', refletir sobre o que se aprendeu por simples exposição, até mesmo pensar sobre o próprio pensamento”. (2001, p. 90). 


\subsection{AUTOBIOGRAFIA E O SI-MESMO E A (RE)CONSTRUÇÃO DA IDENTIDADE}

A "mudança interpretativa" que nossa cultura viveu no século passado fez emergir com ímpeto a interpretação compreensiva ao lado da explicação causal. Contar histórias, buscar através da reflexão diversas interpretações compreensivas de realidades tanto quanto buscar explicações, facilita a tomada de consciência junto com outros (BRUNER, 2001, p. 90-93).

O conceito distribuído do eu ou si-mesmo, segundo Bruner ocorreu com a chamada "virada narrativa", a partir de avanços epistemológicos, antropológicos e sociais em várias áreas. Falando de dentro da Psicologia, Bruner diz que, no mesmo espírito, os psicólogos também "[...] começaram a indagar se o círculo mais amplo de pessoas com quem uma pessoa se importa, ou em quem ela confia, poderia também ser cúmplice das nossas narrativas e das nossas autoconstruções" (1997a, p. 99).

Para Bruner (2001, p. 94), o conhecimento de uma "pessoa” não está apenas “[...] em sua própria cabeça, mas nos apontamentos que ela colocou em livros de anotações acessíveis, nos livros com passagens sublinhadas que se encontram em prateleiras, nos manuais que ela aprendeu a consultar [...]". Neste tempo de novas tecnologias, ele está ainda distribuído “[...] nas fontes de informação que ela colocou em seu computador, nos amigos que ela pode chamar para obter uma referência ou uma orientação, e assim por diante, quase que interminavelmente". Enfim, todas essas coisas, bem como "[...] aquelas formas altamente convencionais de retórica que usamos para justificar e explicar o que estamos fazendo, cada qual talhada e 'armada' [...] pelas circunstâncias de seu uso". Vir a saber alguma coisa, nesse sentido, é tanto estar situado num dado contexto como distribuído. (BRUNER, 2001, p. 94).

Ou seja, é preciso não negligenciar essa natureza situacional-distributiva do conhecimento, pois todo conhecimento possui uma natureza cultural e o processo da aquisição de conhecimento, também possui uma natureza cultural correspondente. "Assim como o conhecimento se prende à rede da cultura, do mesmo modo o si-mesmo se enleia em uma rede de outros si-mesmos, num círculo de cumplicidade e confiança" (BRUNER, 1997a, p. 99).

A Psicologia Cultural, então, impõe duas exigências intimamente relacionadas com o estudo do si-mesmo. Uma delas é que tais estudos devem focalizar os significados em cujos termos o si-mesmo é definido tanto pelo indivíduo (senti- 
do pessoal) como pela cultura na qual participa (significado social) ${ }^{6}$. Entretanto, "[...] isso não é suficiente para que entendamos como um si-mesmo é negociado, pois o si mesmo não é simples resultado da reflexão contemplativa”. Existe uma segunda exigência para esta psicologia, que “[...] está em sintonia com as práticas nas quais os 'significados do si-mesmo' são atingidos e colocados em uso. Estas, com efeito, nos oferecem uma visão mais 'distribuída' do si-mesmo" (BRUNER, 1997a, p. 101).

\subsection{DOIS MODOS DE PENSAMENTO NO SER HUMANO}

Ao detalhar cada uma dessas exigências, Bruner, faz referência aos modos de pensamento ou funcionamento cognitivo: o modo paradigmático ou lógico-matemático e o modo narrativo. Para ele:

Existem dois modos de funcionamento cognitivo, cada um fornecendo diferentes modos de ordenamento da experiência, de construção de realidade. Os dois, (embora complementares) são irredutíveis um ao outro. Esforços para reduzir um modo ao outro ou para ignorar um às custas do outro inevitavelmente deixam de captar a rica diversidade do pensamento. (1997b, p. 12).

O modo paradigmático de pensamento é o modo de funcionamento da ciência moderna, pois ele "[...] trata de causas genéricas, de seu estabelecimento e faz uso de procedimentos para assegurar a referência comprovável e testar sua veracidade empírica.. A linguagem do pensamento paradigmático ou científico é regulada por necessidades de consistência e não-contradição. Seu domínio é definido pelos elementos que podem ser observados, mas também “[...] pelo conjunto de mundos possíveis que podem ser gerados logicamente e testados contra elementos observáveis - ou seja, é conduzido por hipóteses fundamentadas" (BRUNER, 1997b, p. 14).

Seu discurso é descontextualizado, buscando-se generalização. As pesquisas piagetianas, principalmente, contribuíram para a compreensão de como se dá o desenvolvimento deste modo de pensamento no desenvolvimento ontogenético da criança e da própria ciência (PIAGET; GARCIA, 1987).

Segundo Bruner, dispomos de poderosos instrumentos protéticos, desenvolvidos ao longo de milênios, para nos ajudar a executar o trabalho do pensamen-

6 Os termos sentido e significado são aqui utilizados tendo como referência Leontiev, Aléxis. O desenvolvimento histórico do psiquismo. Lisboa: livros Horizonte, 1978. p. 97. 
to paradigmático: lógica, matemática, ciências e computadores e programas de computação que operam "[...] de modo tão suave e veloz quanto possível". Esse tipo de pensamento permite a aplicação imaginativa (intuição) que leva "[...] à boa teoria, à análise profunda, à prova lógica, ao argumento legítimo, à descoberta empírica guiada por hipóteses racionais" (BRUNER, 1997b, p. 14).

Outro modo de funcionamento mental é o dos romancistas, ou seja, o modo narrativo, que trata de ações e intenções humanas ou similares às humanas e das vicissitudes e consequências que marcam seu curso. Entretanto, segundo ele, se conhecemos bastante sobre o pensamento paradigmático, sobre a narrativa, estamos apenas "engatinhando" para compreendê-la.

Bruner reconhece as dificuldades metodológicas que teríamos para cumprir as duas exigências de uma Psicologia Cultural no estudo do si mesmo, anteriormente colocadas (analisar as interpretações dadas tanto pelo sujeito como pela cultura em sintonia com sua prática), mas oferece uma alternativa viável: fazer uma investigação retrospectiva, através de autobiografias, ou seja, “ [...] um relato do que se pensa que se fez, em que cenário, de que modo, por que razão. Ela será inevitavelmente uma narrativa [...] e sua forma será tão reveladora como sua substância”. O que importa é o que "[...] a pessoa pensou que fez, para que ela pensou que fazia alguma coisa, em que tipo de situação ela pensou que estava, e assim por diante" (BRUNER, 1997a, p. 103).

Mas, o que é uma autobiografia? A autobiografia não é de forma alguma, uma construção "livre": além de ser limitada pelos eventos de uma vida, nos estudos realizados por Bruner e colaboradores, ela era "[...] também poderosamente restringida pelos requerimentos das histórias que o contador estava em vias de construir [...]", assumindo formas muito variadas (embora reconhecivelmente culturais).

[...] essas 'autobiografias espontâneas' eram constituídas de histórias menores (eventos, ocorrências, projetos), cada qual adquirindo significado por fazer parte, em maior escala, de uma 'vida'. Nesse sentido, as autobiografias compartilham uma característica universal de todas as narrativas. As narrativas gerais e mais amplas foram contadas em gêneros facilmente reconhecíveis [...]. Os eventos historiados que elas abrangiam, faziam sentido apenas dentro do quadro maior. No centro de cada relato encontrava-se um si-mesmo protagonista em processo de construção: agente ativo, experimentador passivo, ou veículo de algum destino mal-definido. Em conjunturas decisivas surgem 'pontos de mutação', mais uma vez culturalmente reconhecíveis, produzidos quase que invariavelmente pela introdução de uma nova consciência que emerge da vitória ou da derrota, da confiança traída, e assim por diante. 
Tornou-se logo evidente não apenas que a vida imita a arte, mas ela o faz escolhendo como modos de expressão gêneros artísticos e outros dispositivos de narração de histórias. (BRUNER, 1997a, p. 103-4).

Uma narrativa é um discurso e a principal regra do discurso é que deve haver um motivo para que ele seja enunciado. "A narrativa é justificada pelo fato de que a sequência de eventos que ela conta é uma violação da canonicidade: ela conta algo inesperado ou algo que o ouvinte tem motivo para duvidar." Assim, "o 'motivo' da narrativa é resolver o inesperado [...]". Mas, existem outros motivos para se enunciar uma narrativa, entre os quais, podemos destacar alguns: “[...] eliminar a dúvida do ouvinte ou, de alguma forma, corrigir ou explicar o desequilíbrio que [...] fez com que a história fosse contada.. Uma autobiografia, portanto, é uma história que tem dois lados: "uma sequência de eventos e uma avaliação implícita dos eventos contados”. (BRUNER, 2001, p. 119).

\subsection{A TÉCNICA PRIVILEGIADA DE OBTENÇÃO DE AUTOBIOGRAFIAS}

Portanto, a técnica privilegiada de obtenção de é a entrevista. Mas, na maioria das entrevistas, "[...] nós esperamos que os entrevistados respondam as nossas perguntas na forma categórica exigida em diálogos formais, mas não nas narrativas da conversação natural" (BRUNER, 1997a, p.105), uma vez que esta é uma ferramenta projetada para que a ciência formal localize e meça objetos e coisas.

Mas, nós obtemos nossas identidades pessoais (o si mesmo) através do uso da forma narrativa, transformando nossa existência numa totalidade e entendendo-a como uma expressão do desenrolar e do desenvolvimento de uma única história. Acabamos envolvidos por nossas histórias e nunca temos certeza de como elas terminarão.

"Somos constantemente chamados a revisar o enredo à medida que novos eventos são acrescentados às nossas vidas. O si-mesmo, então, não é algo estático ou uma substância, mas uma configuração de eventos pessoais em uma unidade histórica" e esta inclui "[...] não apenas o que fomos, mas também antecipações do que seremos." (BRUNER, 1997a, p. 100).

A autobiografia é, portanto, “[...] um relato apresentado 'aqui e agora' por um narrador, a respeito de um protagonista que leva o seu nome, que existiu no 'lá e então'; a história termina no presente, quando o protagonista se funde com o narrador", mas tendo pela frente um horizonte de possibilidades. Os episódios narrativos que compõem a história de uma vida seguem uma sequência e apre- 
sentam justificativa por excepcionalidade (BRUNER, 1997a, p. 104).

A história mais ampla segue "[...] justificando por que foi necessário (não causalmente, mas moralmente, socialmente e psicologicamente) que a vida tenha tomado um caminho específico. O si-mesmo, como narrador, não apenas relata, mas justifica [...]", sempre com a perspectiva do futuro. À medida que a história vai sendo composta, o narrador realiza uma enorme quantidade de trabalho no "aqui e agora". Geralmente, "[...] o narrador não fala sobre o que passou, que é quase sempre abordado no tempo passado, mas narrativamente, decide o que fazer do passado no próprio momento do relato". O próprio “[...] entrevistador se torna parte daquela 'dispersão de participações' que distribui o si-mesmo entre suas ocasiões de uso". Parte do trabalho em andamento ao se construir uma narrativa pessoal se refere às expectativas do entrevistador ou entrevistadora, de sua persona e do estilo adotado por este ou esta durante a entrevista. Portanto, não se pode ter qualquer ilusão de que um entrevistador pode se manter neutro durante as entrevistas (BRUNER, 1997a, p. 105).

Assim, nesta seção vimos os fundamentos do uso da autobiografia na abordagem psicoculturalista e a seguir vamos apresentar algumas das pesquisas que nosso grupo de pesquisa tem desenvolvido na Amazônia Legal, dentro de programas de pós-graduação.

\section{PESQUISAS EDUCACIONAIS E A ABORDAGEM PSICOCULTURAL}

Uma das pesquisas desenvolvidas na Amazônia Legal na abordagem teórico-metodológica aqui apresentada é a de Azevedo (2014), desenvolvida como dissertação do Mestrado de Psicologia da Universidade Federal de Rondônia. Outra pesquisa é a de Silva (2018) e se trata de uma tese desenvolvida no Doutorado em Educação em Ciências e Matemática da Rede Amazônica de Educação em Ciências e Matemática, resumidas a seguir.

\subsection{A CONSTRUÇÃO DA IDENTIDADE DO ADOLESCENTE DO CAMPO E O ENŚINO DE ARTES}

A pesquisa objetivou compreender o papel da arte na construção da identidade do adolescente em processo de escolarização e de professores que envolvem arte no ensino e aprendizagem em uma escola do campo no município de Ji-Paraná, estado de Rondônia. 
Para a Psicologia Cultural a identidade não é algo fixo, mas corresponde a uma noção de si mesmo, resultante das relações do indivíduo com a cultura. Nessa visão, a construção da identidade/noção de si mesmo, o pensamento e a aprendizagem estão situados na cultura e dependem do uso dos recursos culturais disponíveis.

No caso dos povos do campo e dos professores, essa identidade vem carregada de preconceitos e estereótipos que tentam inferiorizá-los e descaracterizá-los. A desnaturalização e desconstrução de estereótipos, por tanto tempo reproduzidos e legitimados nos discursos, livros didáticos e literários é primordial para resgatar a cultura e ressignificar as identidades.

A pesquisa também mostrou que a escola é o espaço onde as transformações sociais se refletem nas relações humanas presentes nas práticas pedagógicas; um espaço vivo para a inclusão da Arte, como meio para promover a experiência estética, de fruição, fazer artístico, reflexão e contextualização das produções artísticas, contribuindo na redescoberta do indivíduo com suas potencialidades e na (re)construção de sua identidade (AZEVEDO, 2014).

\subsection{LANÇAMENTO DE FOGUETES E A APRENDIZAGEM SIGNIFICATINA DE FÍSICA}

Este trabalho insere-se na problemática da iniciação científica de Física durante a Educação Básica na abordagem psicocultural aplicada à educação proposta por Bruner. Segundo este autor, a escola deveria aproveitar a curiosidade e a criatividade dos alunos para despertar neles o gosto pela ciência viva (processo de pesquisa/descoberta) e a pesquisa teve como objetivo geral investigar o ensino-aprendizagem de Física com estudantes do Ensino Médio, participantes da Mostra Brasileira de Foguetes (MOBFOG) no Instituto Federal de Educação, Ciência e Tecnologia do Mato Grosso (IFMT), campus de Alta Floresta.

A pesquisa foi realizada com 147 alunos do primeiro ano do Ensino Médio integrado aos cursos técnicos em Administração e em Agropecuária do referido instituto que vivenciaram diversas atividades, no contexto da Mostra de Foguetes. A análise dos dados evidenciou que a MOBFOG foi capaz de despertar o interesse dos alunos pelo ensino de Física, mantendo-os ativos durante o processo de aprendizagem. (SILVA, 2018). 


\section{CONSIDERAÇÕES FINAIS}

Três gerações de pesquisadores das regiões Sudeste e Norte veem colaborando mutuamente na produção acadêmica, tanto na área da Psicologia Escolar e Educacional como na área de Ensino de Ciências, numa abordagem teórico-metodológica chamada de Psicologia Cultural ou abordagem psicoculturalista da educação. Este trabalho apresentou os fundamentos desta abordagem e dois trabalhos desenvolvidos nesta perspectiva, dentro de contextos escolares situados na região amazônica, selecionados dentre tantos outros, sendo que alguns já estão publicados e outros não.

As perspectivas de pesquisas educacionais com esta abordagem são muito grandes e a mesma tem se mostrado muito fértil no âmbito de pesquisas escolares e educacionais.

\section{REFERÊNCIAS}

AZEVEDO, S. R. de S. A arte na construção da identidade: um estudo com adolescentes e professores de uma escola do campo em Rondônia. Dissertação (Mestrado em Psicologia) - Universidade Federal de Rondônia, Porto Velho, 2015. Orientadora: Elizabeth Antônia Leonel de Moraes Martines. Disponível em http://www.mapsi.unir.br/pagina/exibir/4873 . Acessado em 21 jul. 2019.

BRUNER, J.S. Atos de significação. Porto Alegre: ArtMed, 1997a.

BRUNER, J.S. Realidade mental, mundos possíveis. Porto Alegre: ArtMed, 1997b.

BRUNER, J.S. A cultura da educação. Porto Alegre: ArtMed, 2001.

LEME, M.I.S. Revisitando a crítica de Bruner: o desvio da proposta cognitivista nos estudos de solução de problemas. Psicologia Reflexão e Crítica, 14, 2, 521536 .

MARTINES, E.A.L.M. O currículo possível no ensino superior: estudo do curso de Ciências Biológicas de uma universidade amazônica. Tese. Doutorado em Psicologia Escolar e do Desenvolvimento Humano. Instituto de Psicologia. Universidade de São Paulo. São Paulo, 2005. Orientadora: Maria Isabel da Silva Leme. Disponível em http://www.teses.usp.br/teses/disponiveis/47/47131/tde22032007-163140/pt-br.php. Acessado em 19 de ago. de 2019.

PIAGET, J.; GARCIA, R. Psicogênese e história da ciência. Lisboa: Dom Quixote, 1987. 
SILVA, T. T. Teorias do currículo - uma introdução crítica. Porto: Porto Editora, 2000.

SILVA, M. L. da. Mostra Brasileira de Foguetes e o uso de mapas mentais como ferramenta avaliativa: estudo sobre ensino de física em cursos integrados do IFMT - Campus de Alta Floresta. Tese (Doutorado em Educação em Ciências e Matemática / Rede Amazônica de Educação em Ciências e Matemática) - Universidade Federal de Mato Grosso. Cuiabá, 2018. Orientadora: Elizabeth Antônia Leonel de Moraes Martines. Disponível em https://www1.ufmt.br/ ufmt/unidade/userfiles/publicacoes/e6039eceb0431d41573662e4374f7fde.pdf. Acessado em 19 de ago. de 2019.

VIGOTSKI, L.S. A construção do desenvolvimento e da linguagem. SP: Martins Fontes, 2000.

\title{
CULTURAL PSYCHOLOGY, AUTOBIOGRAPHY AND EDUCATIONAL RESEARCH: APPLICATIONS IN AMAZON CONTEXT
}

\begin{abstract}
This paper aims to discuss the foundations of the autobiography in Cultural Psychology proposed by Jerome Bruner and to disseminate research that is being conducted in Amazonian school contexts based on this theoretical framework. We consider the proposed theme relevant because Cultural Psychology is not widely used in Brazil and the adoption of research in this perspective allows not only a more complete understanding of psychological functioning, but also the understanding of social processes that differ in their nature from individual functioning. The authors represent three generations of researchers who have been using the foundations and methods of this theoretical-methodological approach in school contexts of the Legal Amazon.
\end{abstract}

Keywords: Cultural Psychology. Autobiography. Applied research 


\title{
PSICOLOGÍA CULTURAL, AUTOBIOGRAFÍA E INVESTIGACION EDUCATNA: APLICACIONES EN EL CONTEXTO AMAZÓNICO
}

\begin{abstract}
Resumen: Este artículo tiene como objetivo discutir los fundamentos de la autobiografía en psicología cultural propuesta por Jerome Bruner y difundir la investigación que se está llevando a cabo en contextos escolares amazónicos respaldados por este marco teórico. Consideramos que el tema propuesto es relevante porque la Psicología Cultural no se usa ampliamente en Brasil y la adopción de la investigación en esta perspectiva permite no solo una comprensión más completa del funcionamiento psicológico, sino también la comprensión de los procesos sociales que difieren en su naturaleza del funcionamiento individual. Los autores representan a tres generaciones de investigadores que han estado utilizando los fundamentos y métodos de este enfoque teórico-metodológico en contextos escolares de la Amazonía Legal.
\end{abstract}

Palabras clave: Psicología cultural. Autobiografía. Investigación aplicada. 